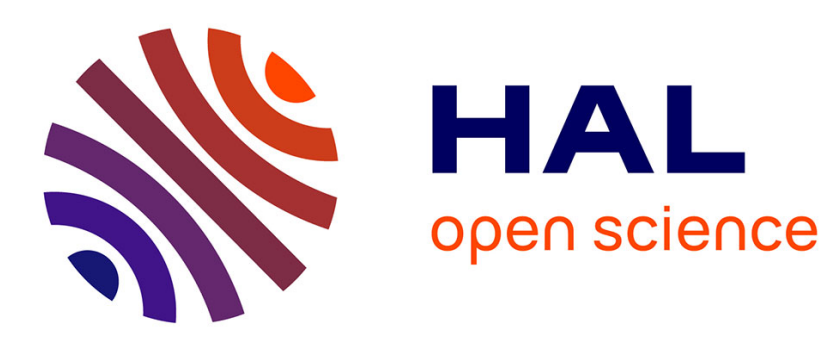

\title{
Discrete Choice Decision-Making with Multiple Decision Makers within the Household
}

André de Palma, Nathalie Picard, Ignacio Inoa

\section{To cite this version:}

André de Palma, Nathalie Picard, Ignacio Inoa. Discrete Choice Decision-Making with Multiple Decision Makers within the Household. 2014. hal-00969216

\section{HAL Id: hal-00969216 https://hal.science/hal-00969216}

Preprint submitted on 2 Apr 2014

HAL is a multi-disciplinary open access archive for the deposit and dissemination of scientific research documents, whether they are published or not. The documents may come from teaching and research institutions in France or abroad, or from public or private research centers.
L'archive ouverte pluridisciplinaire HAL, est destinée au dépôt et à la diffusion de documents scientifiques de niveau recherche, publiés ou non, émanant des établissements d'enseignement et de recherche français ou étrangers, des laboratoires publics ou privés. 
DISCRETE CHOICE DECISION-MAKING WITH MULTIPLE DECISION MAKERS WITHIN THE HOUSEHOLD

André de PALMA

Nathalie PICARD

Ignacio INOA

Cahier n ${ }^{\circ}$ 2014-10

\section{DEPARTEMENT D'ECONOMIE}

Route de Saclay

91128 PALAISEAU CEDEX

(33) 169333033

http://www.economie.polytechnique.edu/

mailto:chantal.poujouly@polytechnique.edu 


\title{
Discrete Choice Decision-Making with Multiple Decision Makers within the Household
}

\author{
André de Palma ${ }^{13}$, Nathalie Picard ${ }^{23}$, Ignacio Inoa ${ }^{2^{*}}$ \\ ${ }^{1}$ Ecole Normale Supérieure de Cachan, Centre d'économie de la Sorbonne ${ }^{\dagger}$ \\ ${ }^{2}$ Université de Cergy-Pontoise, THEMA ${ }^{\ddagger}$ \\ ${ }^{3}$ Ecole Polytechnique, Département d'Economie ${ }^{\S}$
}

\begin{abstract}
There is still a long way to achieve the goal of providing a theoretical and empirical framework to model and apply economics of the family. Decision-making within the family has been neglected too long in transportation. Two special issues by Bhat and Pendyala, 2005 [17] and by Timmermans and Junyi Zhang, 2009 [81] provide the most notable exceptions. The objective of this paper is to set-up a flexible framework to discuss the development of integrated transportation models involving interacting and interdependent actors; updating previous reviews from the point of view of economics of the family. Transportation is very keen to have access to this type of models, since their applications are numerous. Let mention, for example, residential location choice, workplace choice, car ownership, choice of children's school, mode choice, departure time choice activity patterns and the like. The (non unitary) economics of the family models are totally different models, which do not merely extend existing discrete choice models. They introduce new concepts, which are specific to within family interactions: negotiation, altruism, or repeated interaction and Pareto optimality. This review is completed with the study of different types of accessibility measures including recent work on timegeography measures of accessibility.
\end{abstract}

\footnotetext{
"We would like to thank Stephen Hess and one anonymous referee for their useful comments.

† 61 Av. du Président Wilson, 94230 Cachan Cedex France; andre.depalma@enscachan.fr.

† 133 Bd. du Port, 95011 Cergy-Pontoise Cedex, France; nathalie.picard@u-cergy.fr; ignacio.inoa@u-cergy.fr.

${ }^{\S}$ Route de Saclay, 91128 Palaiseau, France.
} 


\section{Introduction}

Different research streams concerned with household decision-making have developed independently in different disciplines. The corresponding papers consider topics such as labour supply, transportation decisions, time and task allocation, or residential and employment choices. Literature in these fields has been dominated by models in which the household is treated as a single decision-making unit or unitary models (see Timmermans, 2009 [79] for an extensive review on past research in the transportation literature, and Vermeulen, 2002a [84], 2002b [85] for a literature review on unitary and collective household models, and Bianchi and Robinson, 1997 [18] for sociological study of time use within the household). In collective models, the different household members are engaged in a joint decision process involving bargaining. Until recently, interactions within the household were not explicitly modelled and the decision-making process outcome was considered as resulting from a representative individual (as if the household were a black box which needs not to be opened). In such models, household interactions were either introduced through explanatory variables defined at the household level, or simply disregarded in models of activity-travel demand (see Srinivasan and Bhat, 2005 [75]). Examples of household-level explanatory variables like number of household members, of active members, of children, household income, and other household dummy variables (e.g., occupational status, property status, age, etc.) are provided in Townsend, 1987 [82] or in Golob and McNally, 1997 [40], among others.

However, many household decision-making processes involve more than one decision maker who cannot be reduced to a single agent. Note that even when the decision problem under scrutiny does not involve multiple decision makers, most of the individual decisions depend, directly or indirectly, on the choices made by other household members (Timmermans and Zhang, 2009 [81]). A growing body of research in different fields, ranging from transportation demand to labour economics, has recently started to explicitly take into account the interactions between household members, and to model the corresponding strategies. The distinction between discrete and continuous household decisions is at the core of these new theoretical and empirical developments. Van Soest, 1995 [83] proposed a discrete choice model of labour supply disregarding the negotiation process within the household, whereas collective models of time allocation and labour supply focus on this negotiation process in discrete 
(Vermeulen, 2006 [86]) or in continuous-discrete applications (Blundell et al., 2007 [22]). The modelling of within-family interactions took off in the transportation literature with the special issues on modelling intra-household interactions edited by Bhat and Pendyala, 2005 [17] and by Timmermans and Zhang, 2009 [81]. In a nutshell, Bhat and Pendyala, 2005 [17] focus on contributions based on utility-maximizing models, whereas Timmermans and Zhang, 2009 [81] present work that "adopt diverse methodologies" as group decision theory, and microsimulation approaches. There are a few contributions using experimental economics methodology to compare the decisions taken by the husband alone, the wife alone, and then by the spouses together (see Bateman and Munro, 2005 [5], Beharry-Borg, Hensher and Scarpa, 2009 [13] or de Palma, Picard and Ziegelmeyer, 2011 [65]). However, they do not analyse the decision mechanism within the couple.

A careful review of the literature reveals two main streams of research using the discrete choice framework to model household decision-making processes in multi-person households (several decision makers), with an explicit modelling of within-family interactions. In these studies, household decision-making models are developed in a discrete choice framework or with discrete choice (econometric/empirical) applications. The first research stream is related to collective models and their discrete labour supply model applications. The second research stream covers the transportation, activity-demand and location literature. These streams will be described in the following sections.

Section 2 explains the difference between individual and family models, and provides a transition from unitary to collective and negotiation models, with a special focus on labour supply models. The transportation and activity-travel demand literature with intra-household interactions is presented in Section 3. Section 4 describes the location and accessibility contributions considering multiple decision makers within the households, while Section 5 concludes.

\section{Individual versus Family Models}

There are two cases when it becomes relevant (and often necessary) to switch from individual decision-making models to family decision-making models. The first case is when the choices themselves are relevant to the family (marriage, divorce, number of children). The second case 
is when individual choices generate externalities to the other members of the household (competition among family members for using a joint car, joint leisure, chores sharing, spatial mobility, retirement plans...).

Current research on family economics aims at providing the best representation of the household decision-making process, when the household is made of several decision-makers. In the simplest (unitary) models, the household is considered as the unique decision unit, whereas in the most elaborate models, each household member is characterized by specific preferences, and the household decisions result from the confrontation (or aggregation) of these individual preferences.

\subsection{Individual Choices about Consumption and Work}

Traditionally, family economics describes household behaviour, focusing on choices concerning consumption and work. In order to examine these questions, the household is described as a small production unit combining domestic time with intermediary goods bought on the market in order to produce some commodities, which are in turn consumed by household members). These developments have allowed economists to answer old but important questions related to major socio-demographic changes over the twentieth century, such as the change in domestic working hours (Gronau, 1977 [42]) and female labour supply, the growing divorce rate (Becker, Landes, and Michael, 1977 [11]), or the diminishing fertility rate (Becker and Lewis, 1973 [12]). The description of household behaviour may rely on contributions from various disciplines such as sociology, demography or ethnology (see Picard, 1999 [66]). The topics under study go far beyond consumption or work choices. However, the way of representing household decisions in family economics until the late 80 's is not very far from that of "traditional" models of consumption and labour supply, since these models generally neglect the multiplicity of decision-makers.

The methodology traditionally used in family economics is quite straightforward. A (unique) household utility function describes the household preferences, taking as arguments the quantity of goods consumed (including local amenities when location choices are at stake) and/or leisure time. This function is maximized under a unique budget constraint aggregating the resources and expenses of all household members (and possibly a unique aggregated time 
constraint). The maximization of household utility determines the relevant demand functions. This procedure can be used for assessing the effects of economic policies on individual behaviour and welfare. For example, Hausman, 1981 [46] estimates the effect of a variation in marginal taxation rates on hours worked, and measures the cost of the US taxation system in terms of welfare.

\subsection{Family Economics in Unitary models}

In the "unitary model", the household is considered as a unique decision-maker, and no attention is devoted to the complexity of the decision-making process and of the numerous transactions between family members. As pointed by Nobel Prize laureate Amartya Sen, 1983 [72], in the unitary models literature, the household members are incorporated into a "glued together family". Following the impulsion originated from seminal work by Nobel Prize laureate Gary Becker (1965 [6]; 1973 [7]; 1974 [9]; 1991 [10]), recent developments in family economics broadens the classical research field to new questions such as the marriage decision or choices related to the number of children, their education, and the allocation of tasks and time among household members.

In unitary models, any difference in the demographic structure (e.g. differences between a single person and a couple with or without children) is either totally ignored, or simply reflected in ad hoc equivalence scales.

In addition, any conflicting situations that might arise among members (affecting the decisionmaking process) are disregarded. The unitary model indeed neglects the diverging interests that may arise among household members, and implicitly assumes that these members pursue consensual objectives, leading to a poor understanding (and thus modelling) of decision mechanisms (and therefore, of resources allocation) within the household. This generates three kinds of drawbacks. The first drawback is a wrong interpretation of empirical results. For example, Lise and Seitz, 2011 [56] show that failing to consider changes in the intrafamilial distribution of consumption leads to a major overestimation of inequality growth over the last 40 years in the UK. This bias should be taken into account in any poverty-reducing policy, and its recognition would lead to a fundamental rethinking of the change in intrafamilial distribution of consumption. The second drawback is a wrong assessment of the effects of economic policies 
on the well-being of each household member, concerning for example a change in the income taxation system. Lundberg, Pollak, and Wales, 1997 [58] illustrate the importance of these questions for family policy, and show that a shift of family benefits from the father to the mother during the 70s in the UK was followed by a rise in the demand for women's and children's clothes. This indisputable empirical result is inconsistent with the "unitary model" of the household in which every member has the same objective function. The third drawback is a poor predictive power of unitary models and a biased evaluation of behavioural effects of economic policies.

Unitary models implicitly or explicitly assume that the household is the basic decision unit, and acts as a unique decision-maker. In multi-person households, this implies that members are supposed to act as if the household preferences could be represented by a unique utility function, maximized under a unique budget (and time) constraint. The consensus model proposed by Samuelson, 1956 [70] could provide some justification of this unitary description, under very restrictive and unrealistic assumptions. Another attempt to legitimate the unitary approach was made by Becker, 1974 [8], with his famous "rotten kid" theorem. It basically states that, if there is a "benevolent dictator" in the family, then all family members, even if they are selfish, will act to maximize the same utility function as the benevolent dictator. The key assumption is that the benevolent dictator transfers money to each family member. All members then want to please the benevolent dictator in order to receive a larger transfer. However, Bergstrom, 1989 [16] later stressed that this attempt to justify unitary models relies on too arbitrary and unrealistic assumptions (especially the assumption about transfers). Moreover, theoretical predictions derived from unitary models, such as income pooling, are often in contradiction with empirical data. Income pooling means that household decisions depend on household total resources, but not on the distribution of these resources among family members. This prediction comes from the assumption of a unique budget constraint defined at the household level, and a unique household utility function to be maximized. Income pooling has been rejected, for example, by Thomas, 1990 [78], who showed that the relative contributions of men and women to the household income influence household decisions. 


\subsection{Family Economics in collective and other bargaining models}

Collective models and other within-households bargaining models aim at answering the theoretical and empirical criticisms addressed to unitary models of family decision-making. They developed in two major directions.

"Strategic" models rely directly on the theory of non-cooperative games (see, e.g. Ashworth and Ulph, 1981 [4], Leuthold, 1968 [55]), while "collective" models proposed by Chiappori 1988 [25], 1992 [26] rely on the basic assumption that the household decision process leads to Paretoefficient allocations. The bargaining process may then be either explicit (as in McElroy and Horney, 1981 [59], or in Lundberg and Pollak, 1993 [57]), or non-specified (as in Chiappori, 1988 [25], 1992 [26]). In the latter case, the bargaining process is very general and not restrictive, only assuming Pareto-optimality.

Pareto-optimality hypothesis seems natural for analysing household decisions since family members, who interact over a long period, are probably able to find mechanisms leading to efficient decisions.

Collective models can be used to study the welfare level of each household member, and therefore to analyse and measure in a consistent way the redistributive effects of any economic policy, not only at the household level but also at the individual level. Indeed, recent theoretical results show that, under some rather plausible conditions, individual utility functions can be recovered from household behaviour (and disentangled from bargaining power effects, whereas bargaining effects induce a bias in the measurement of preference parameters in unitary models).

This evaluation of economic policies offers promising research avenues, especially in the context of urban development or transportation policies.

\subsection{Labour supply models within the family}

Examples of applications of the two-adult model are provided by Hausman and Ruud, 1984 [45]; Ransom, 1987 [69]; Bloemen, 1989 [20]; Kapteyn, Kooreman, and van Soest, 1990 [48]. In these models, hours worked by the two spouses are treated as mixed discrete and continuous random variables, whereas in van Soest, 1995 [83] they are treated as discrete, which allows easily 
incorporating nonlinear taxes, joint filing, fixed costs of working, unemployment benefits, hours restrictions, unobserved wage rates of non-workers, and random preferences, etc., without challenging model tractability. The models are estimated using smooth simulated maximum likelihood relying on Gourieroux and Monfort, 1993 [41].

The method is illustrated by several policy simulations. Unfortunately, it assumes a unitary model, which neglects the effect of the policy on respective bargaining powers, and may therefore lead to severe bias in labour supply reactions.

In the collective models (Chiappori, 1988 [25]; Chiappori, 1992 [26]), the only assumption made about the decision-making process is the Pareto efficiency (optimality of decisions). That is, the decision-making process involving more than on household member leads to allocations such that it would not be possible to make one household decision-maker better-off, without making at least another household decision-maker worse off. The collective models are very general in the sense that they do not rely on a restrictive specific bargaining process, and they do not assume any restrictive functional form for each member preferences. Collective models have proved at many occasions to perform better than the usual unitary models to explain observed behaviour (Vermeulen, 2002a [84]).

Collective models of labour supply have been developed for two-earner households (e.g., Fortin and Lacroix, 1997 [37]; Moreau and Donni, 2002 [62]; Chiappori, Fortin, and Lacroix, 2002 [28]) in a continuous framework. However, the interest here is limited to the models in which utility functions are directly estimated and household labour supply is considered as a discrete choice problem. The contributions of Van Soest, 1995 [83], Bingley and Walker, 1997 [19] and Keane and Moffitt, 1998 [49] are the first ones to use a discrete choice framework to study labour supply, but this was done in the context of a unitary model.

Van Soest, 1995 [83] developed a joint labour supply model for two spouses, in which the budget set is discrete. The discretization of the budget set allowed for incorporation of nonlinear taxation and non-convexities, which gave rise to a series of discrete collective labour supply models, starting with Laisney, 2002 [53] and subsequently with Vermeulen et al., 2006 [87], Vermeulen, 2006 [86], and Blundell et al., 2007 [22]. Laisney, 2002 [53] considers household labour supply as a discrete choice problem, and integrates non-participation and 
nonlinear taxation. Vermeulen et al., 2006 [87], develop a discrete choice collective model and solve it using a procedure mixing calibration and estimations. Blundell et al., 2007 [22], consider a model in which the male labour supply is discrete, whereas the female labour supply is continuous. Vermeulen, 2006 [86], models female labour supply in a discrete choice framework considering male labour supply as given, and including non-participation and nonlinear taxation. Other discrete collective models of labour supply include Callan, Van Soest, and Walsh, 2009 [24]; Bloemen, 2010 [21]; Haan, 2010 [43]; Michaud and Vermeulen, 2011 [60]; Pacifico, 2012 [64].

\section{Intra-household interaction and group decision-making models}

The main research stream applying discrete choice models to household decisions involving multiple decision-makers has been developed in the transportation literature. It includes the socalled intra-household interaction and group decision-making models of transportation, activitydemand, and location choices. Intra-household interaction models study how the household decides in the long run and in the short run. More precisely, these models take into account the interdependencies between residential location and workplace of household members (long term), or between activities and travel patterns (short term). Intra-household interaction models are interested in studying, for example, which activities are conducted in a day or over several days by the household members (sharing maintenance responsibilities, household cars, and pick-up and drop-off); when, where, by whom and with whom the activities are performed (joint or independent engagement on activities); and how job types and job locations of the different household members affect professional and residential mobility and location decisions of the household.

The general research stream concerned with intra-household interaction and group decisionmaking models of transportation, activity-demand, and location choices research stream can be subdivided into two interconnected subfields of study. The first subfield is concerned with choices in a long-term decision context (i.e. residential location and mobility; job location and mobility, car ownership). Abraham and Hunt, 1997 [1]; Freedman and Kern, 1997 [38]; Sermons 
and Koppelman, 2001 [73] and Waddell, 1996 [92] have analysed residential and professional location choices as resulting from a multiple-worker household decision-making process.

The second subfield is made of studies concerned with choices in a short-term decision context: the activity-travel demand literature (i.e. mode choice, travel behaviour, car sharing, and task allocation and activity based models). This literature develops models of task allocation, decisions related to joint travel and activity participation, mode choice, car sharing and so on. Discrete choice modelling on these topics has been studied by Wen and Koppelman, 1999 [94], 2000 [95]; Gliebe and Koppelman, 2002 [39]; Scott and Kanaroglou, 2002 [71]; Vovsha, Petersen, and Donnelly, 2003 [89]; 2004a [91]; 2004b [90]; Bradley and Vovsha, 2005 [23]; Srinivasan and Athuru, 2005 [74]; Srinivasan and Bhat, 2006 [76], among others.

The work of Gliebe and Koppelman, 2002 [39]; Scott and Kanaroglou, 2002 [71]; Vovsha, Petersen, and Donnelly, 2003 [89]; Srinivasan and Bhat, 2006 [76] concerns the decision to participate in an activity jointly or independently from other household members. Gliebe and Koppelman, 2002 [39] model independent activity participation, allocation of time to joint activities, and the interplay between individual and joint activities using a proportional share model. Scott and Kanaroglou, 2002 [71] develop a trivariate (by household type) ordered probit to model the number of non-work, out-of-home activity episodes for household heads.

The work concerned with task allocation (of maintenance activities) is better represented by discrete choice model systems that are embedded in tour-based travel demand modelling systems. On the one hand there is the discrete choice system of Vovsha, Petersen, and Donnelly, 2003 [89]; 2004a [91]; 2004b [90] that is the joint travel model component that makes part of the Mid-Ohio Regional Planning Commission. On the other hand there is the discrete choice system of Bradley and Vovsha, 2005 [23] that is part of the activity-based model of the Atlanta region.

Bradley and Vovsha, 2005 [23] survey the contributions on activity-travel demand literature, in which either intra-household decision-making is not considered explicitly, or discrete choice model techniques are not used.

The attention is restricted here to theoretical or empirical developments that consider a discrete choice modelling strategy in activity-travel demand models accounting for 
interpersonal dependencies in multiple decision-makers households. However, the activitytravel demand literature has also used seemingly unrelated regressions (SUR) and structural equation modelling (SEM) to account for household interactions (see Srinivasan and Bhat, 2005 [75]). These approaches usually develop a SUR or SEM system of two or more equations corresponding to the time invested in activities by the household head and the other members in consideration (household head spouse and/or children or other active household members).

Other classifications of activity-travel demand models that account for interpersonal dependencies in households with multiple decision makers have been proposed. For instance, Timmermans, 2009 [79] classifies activity-based travel demand models that explicitly consider interactions within households with multiple decision makers into three categories: microsimulation, rule-based and utility-maximizing models. Micro-simulation models simulate a household member daily activity-travel pattern using algorithms that replicate the observed patterns from data (including time constraints and actual decision-making outcome) giving timing and sequence of activities schedules that account for household's and personal's characteristics (see, e.g., Pribyl and Goulias, 2005 [68]). The second category of models is referred to as the rule-based models. They build multi-agent computational processes in which the individual activity-travel decisions reflect "if-then" decision tree structures, regarding which activities, with whom, and for how long the activities are conducted (see, e.g., Arentze and Timmermans, 2004 [3]).

Timmermans' last category of models corresponds to the utility-maximizing models. He further subdivides utility-maximizing models into those using the discrete choice approach (based on the random utility models) and in those using the time allocation approach. Time allocation models are based on a group utility function. This function is a linear function of individualspecific terms and of interaction terms that reflect the interactions between different individuals in a multiplicative form. The household then allocates its time to activities such that its utility would be maximized given individual time constraints (see, e.g. Zhang and Fujiwara, $2006[98])$. 


\section{Location and Accessibility}

Lee et al, 2010 [54] categorized accessibility measurement approaches into four groups: the proximity based (measured in term of travel time, distance, etc.), the gravity-based (derived from the denominator in the gravity model), the cumulative opportunities approach (as a special case of the gravity-based measure), and the utility-based approach (denominator of the MNL model). See Lee et al, 2010 [54] for more details on this classification and for further references.

The utility-based approach allows for the development of disaggregated or individual-specific accessibility measures captured in the log-sum variable when the nested logit formulation is used. See Ben-Akiva and Lerman, 1979 [14]; Srour et al., 2002 [77]; Waddell and Nourzad, 2002 [93]; and Zondag and Pieters, 2005 [99] among others.

A major determinant of household location is accessibility. Accessibility to jobs measures the spatial proximity of the residential location to the job location. In the absence of income effects, and with a Logit demand function, the accessibility is measured by a log-sum term, which is a measure of consumer surplus. In the Logit case, accessibility corresponds to the expected maximum utility, which is equal to the Logarithm of the denominator of the Logit demand function. It is easy to see that when the utility is additive in income, the derivative of the accessibility is the demand function. This is a direct application of Roy's identity (Anderson, de Palma, and Thisse, 1992 [2]). The same property is true for the Generalized Extreme Value case, provided that the utility is additive in income (and, as a consequence, there are no income effects). The reader is referred to Anderson, de Palma, and Thisse, 1992 [2]; and de Palma and Kilani, 2007 [31] for details.

In the homogenous case, all agents have the same preferences (this means in particular, the same values of time and the same preferences for jobs), and therefore have the same measure of accessibility. In the heterogeneous case, the accessibility depends on household characteristics and in particular on the value of time.

Research on residential location has commonly used accessibility as an aggregated measure of ease of access to jobs or people in choice models where the household is considered as a single decision-making unit (individual or unitary approach). By contrast, Chiappori, de Palma, Picard 
and Inoa, 2013 [27] have studied residential location of households including two active spouses. In the context of a collective model assuming Pareto-optimality, they measure simultaneously spouses' respective values of time and bargaining powers. They show that neglecting bargaining powers can lead to a bias in the estimated values of time which may reach $20 \%$. The order of magnitude of this bias is comparable to the male-female difference in values of time. Similarly, Picard et al., 2013 [67] measure simultaneously spouses' respective values of time and bargaining powers in a joint mode choice model.

In the individual or unitary approach, accessibility has been (1) studied in single and multipleworker location choice models, (2) measured using different approaches, and (3) used as an indicator of non-work activities. We develop in the following subsections these three issues on the use and measurement of accessibility measures.

\subsection{Accessibility Measures From Multiple Worker Location Choice Models}

The study of the interactions between household members within a household in residential location choice models has allowed the differentiation of accessibility measures by sociodemographic characteristics, identifying differences between females and males, and between multiple-worker households and one-worker households. The reference studies of multipleworker residential location choice models are the works of Timmermans et al., 1992 [80], Abraham and Hunt, 1997 [1], Freedman and Kern, 1997 [38], and Sermons and Koppelman, 2001 [73]. Note that Timmermans et al., 1992 [80] studied the residential location choice of two-worker households but using a nine-step (decompositional) joint choice model.

Abraham and Hunt, 1997 [1] used a logit model structure with a system for weighting the contributions of different workers to the household utility in a three-level nested logit (residential location, workplace, and mode choice). Freedman and Kern, 1997 [38], analyses residential location and workplace with a joint logit model where a two-worker household jointly chooses residential location and both spouses workplace to maximize utility, subject to budget and time constraints. Sermons and Koppelman, 2001 [73] develop a multinomial logit model of residential location choice to study differences between males and females in sensitivity to commuting time for two-worker households. 
In general, these studies showed that females are more sensitive to commuting time and accessibility measures than males. Demographic characteristics such as presence of children, workplace status, and spouses' occupation and workplace location, are determinants for commuting time and accessibility measures, and therefore residential location choices in a multiple worker household.

\subsection{Individual-specific Accessibility Measures}

Despite the variety of contributions to the study of residential location, little has been said regarding the influence of job type on the individual-specific accessibility to jobs, and therefore on the residential location and workplace choices when individuals are considered forwardlooking. Household members choose a workplace conditional on their current residential location, while also considering the future changes on workplaces when choosing their residential location.

Inoa, Picard, and de Palma, 2014 [47] have elaborated a three-level nested logit model that allows to study the interdependency of residential location and workplace, while accounting for variation of preferences for job types across individuals. Residential location is the upper level choice, and workplace and job type are the middle and lower level choices, respectively. With this nested structure, an individual-specific accessibility measure is constructed, which corresponds to the expected maximum utility across all potential workplaces and job types. When considering accessibility to jobs, the choice of a particular workplace depends on the distribution of jobs by type, which are valued differently by different workers. Their modelling of the job type choice allows them to compute an individual-specific measure of attractiveness to job types (log-sum variable) and to use it in the workplace location choice model.

Using data from the Paris Region Census, Inoa, Picard, and de Palma, 2014 [47] find that the individual-specific job type attractiveness measure is a more significant predictor of workplace location than the standard total number of jobs measure. Most importantly, the individualspecific accessibility measure is an important determinant of the residential location choice, and its impact on the residential location choice strongly depends on gender, fertility, age, and education. Some resulting individual-specific accessibility maps are displayed in Annex. They show that accessibility is more equally distributed over the region for the lowest education 
level, whereas it is more concentrated in the Central business district for the most educated workers.

\subsection{Time Geographic Measures of Accessibility}

\subsubsection{Activity Pattern Models}

The literature on residential location has not restricted accessibility to the concept of proximity to jobs. It has also studied the accessibility to different (non-work) activity opportunities and measured their respective influence on residential location. Activity-travel demand and task allocation models are concerned with the activity patterns of households and individuals all over a day (and even all over a week, in the new activity-based time use data sets). Capturing nonwork accessibility is therefore essential when modelling in-home and out-of-home activity patterns and trip chaining (Neutens et al., 2012 [63]). Accessibility measures adapted for these models can be found in the framework of time geographic measures of accessibility.

Hägerstrand, 1970 [44] introduced the concept of time-space prism (TSP) in order to describe the temporal and spatial constraints in which individuals travel to and participate in activities. Time-space prisms define the locations that an individual can reach given a time budget. The area shaped by the potential locations that the individual can reach in a given time gap is referred to as the potential path area (PPA). A thorough study of the time-geographic measures can be found in the work of Miller, 1991 [61] and Kwan, 1998 [52]. Kim and Kwan, 2003 [50] provide a review on accessibility measures used in empirical settings derived from the timespace prism.

There exist only a few applications where time-geographic measures of accessibility have been used in the literature under consideration here, that is, discrete choice location models and activity-travel demand and time allocation models that consider intra-household interactions. Among these applications are the work of Lee et al., 2010 [54]; Yoon and Goulias, 2009 [97], 2010 [96]; Kitamura et al., 2001 [51]; Ettema, 2006 [36].

Lee et al., 2010 [54] developed a discrete choice residential location model that includes a disaggregated accessibility measure to non-work activities (derived from the TPS framework), while also accounting for the accessibility to jobs. Yoon and Goulias, 2009 [97], 2010 [96] 
developed a structural equations model of activity and time allocation that consider intrahousehold interactions in households without child only and then in households with and without child where the accessibility measure used is based on time geography. Using timegeographic accessibility measure, Kitamura et al., 2001 [51] studied the influence of travel patterns and residential location on car ownership; and Ettema, 2006 [36] developed a discrete continuous Tobit model of activity participation and duration.

\subsubsection{Dynamic Transport Models}

The time geographic models described above neglect the interactions between households. However, such interactions are important in the case of congested cities and they evolve across time and geography. Such externalities are analyzed in dynamic transport models.

METROPOLIS is a dynamic model which describes mode choice, route choice and departure time choice (see de Palma and Marchal, 2002 [35]; de Palma, Kilani, and Lindsey, 2005 [32]; and de Palma and Lindsey, 2006 [33]). It is dynamic in the sense that congestion depends on the time of the day. It uses a nested logit model, where the mode choice is made at step one, while departure time choice is made at step two.

The departure time choice is given by a continuous logit model, with the log-sum formula as the welfare measure. In this case, the mode choice model, at the upper level, depends on the accessibility at the lower stage. Consider a user going from origin $i$ to destination $j$. The attractiveness of this car user (the formula is similar for the public transportation users) is:

$$
A_{i j}(t)=\int_{0}^{T} \exp \left[-C_{i j}(u) / \mu\right] d u,
$$

where $C_{i j}(u)$ represents the generalized cost of an individual using private transportation, and $u$ (and $t$ ) denote the departure time. Following Vickrey, 1969 [88], this generalized cost is given by:

$$
C_{i j}(u)=\alpha t t_{i j}(u)+\beta\left(t^{*}-u-t t_{i j}(u)\right)^{+}+\gamma\left(u+t t_{i j}(u)-t^{*}\right)^{+},
$$

where $\alpha$ is the value of time, $\beta$ is the unit schedule delay early parameter, $\gamma$ is the unit schedule delay late parameter, $t^{*}$ is the desired arrival time at destination and $t t_{i j}(u)$ is the travel time given the departure time $u$. Such measure is potentially useful for other applications, such 
as activity choice, or residential location. In the latter case: the log-sum aggregation over the destinations $j$ provides a potential user benefit of residential location at $i$.

In the case of couples, the value of time of the man may not be the same in the case his spouse is at home at the time he leaves and in the case she leaves before him, and vice versa. In that case, the generalized cost function of the man depends on the departure time of the woman, and the generalized cost function of the woman depends on the departure time of the man. The resulting within-family externalities have been studied by de Palma, Picard, and Lindsey, 2012 [34]. They showed that, although cooperation is clearly beneficial for couples themselves, it may exacerbate congestion and thus worsen negative externalities between families.

\subsection{Interactions within families outside the household}

Compton and Pollak, 2009 [29] have analysed interactions within larger families, living in different households. They describe and analyse the patterns of proximity and co-residence involving adult children and their mothers using data from the National Survey of Families and Households (NSFH) and the U.S. Census. Their idea is that the ability of family members to engage in intergenerational transfers of hands-on care requires close proximity or co-residence. They find that, in spite of the decline in intergenerational co-residence in the United States, most Americans still live within 25 miles of their mothers, and even closer for the lowest educational levels. Individual characteristics such as age, race and ethnicity affect both the probability of co-residence and close proximity, and their effect depends on gender and marital status, indicating the need to model the corresponding categories separately.

Compton and Pollak, 2011 [30] further show that close geographical proximity to mothers or mothers-in-law has in turn a substantial positive effect on the labour supply of married women with young children. They argue that proximity increases labour supply through the availability of childcare. Their interpretation of availability is there broad enough to include not only regular scheduled childcare during work hours but also an insurance aspect of proximity (e.g., a mother or mother-in-law can provide irregular or unanticipated childcare). Using large American datasets, they find that the predicted probability of employment and labour force participation is 4-10 percentage points higher for married women with young children living in close proximity to their mother or their mother-in-law compared to those living further away. 


\section{Conclusion and extensions}

There is still a long way to achieve the goal of providing a theoretical and empirical framework to model and apply economics of the family models. Decision-making within the family has been neglected too long in transportation. Two special issues by Bhat and Pendyala, 2005 [17] and by Timmermans and Junyi Zhang, 2009 [81] provide the most notable exceptions. We also refer the reader to the discussion on group behavior, held at $11^{\text {th }}$ International Conference on Travel Behavior Research (Kyoto), and organized by J. Zhang and A. Daly (Timmermans, 2009 [79]).

The objective of this paper was to set-up a flexible framework to discuss the development of integrated transportation models involving interacting and interdependent actors. Transportation is very keen to have access to this type of models, since their applications are numerous. Let mention, for example, residential location choice, workplace choice, car ownership, choice of children's school, mode choice, departure time choice activity patterns and the like. The (non unitary) economics of the family models are totally different models, which do not merely extend existing discrete choice models. They introduce new concepts, which are specific to within family interactions: negotiation, altruism, or repeated interaction and Pareto optimality.

It is our belief that that activity pattern, mode choice, allocation of time, residential and job location choices, as well as departure time choice, cannot be analysed in the family, without the idea that there are almost always conflicting interests, given the budget and the time constraints of the different family members. Therefore, some coordination and cooperation is needed to achieve common goals, even if the cost borne by spouses is often not identical. The transportation field has made large advances in this area, but the connection with the theoretical and the econometric model are still open.

The group behavior discussion in the $11^{\text {th }}$ International Conference on Travel Behavior Research showed that cross-fertilization between the economics of the family and the transportation field is needed (). We hope that this chapter will provide a first step to fulfil this gap. Some preliminary discussion on how to integrate bargaining and collective models in transportation and urban economics can be found in Ben-Akiva et al., 2012 [15]. 


\section{References}

[1] John E. Abraham and John D. Hunt. Specification and estimation of nested logit model of home, workplaces, and commuter mode choices by multiple-worker households. Transportation Research Record, 1606:17-24, 1997.

[2] Simon Anderson, André de Palma, and Jacques-Francois Thisse. Discrete Choice Theory of Product Differentiation. Cambridge, MA: The MIT Press, 1992.

[3] Theo A. Arentze and Harry J.P Timmermans. A learning-based transportation oriented simulation system. Transportation Research Part B: Methodological, 38(7):613 - 633, 2004.

[4] John S. Ashworth and D.T. Ulph. Household models. In C.V. Brown, editor, Taxation and Labor Supply, George Allen and Unwin, London, pages 117-199.

[5] Ian Bateman and Alistair Munro. An experiment on risky choice amongst households. The Economic Journal, 115(502):pp. C176-C189, 2005.

[6] Gary Becker. A theory of the allocation of time. The Economic Journal, 75(299):493-517, 1965.

[7] Gary Becker. A theory of marriage: Part i. Journal of Political Economy, 81(4):813-846, 1973.

[8] Gary Becker. A theory of marriage: Part ii. Journal of Political Economy, 82(2):S11-S26, 1974.

[9] Gary Becker. A theory of social interactions. Journal of Political Economy, 82(6):10631093, 1974.

[10] Gary Becker. A Treatise on the Family. Harvard University Press, 1991.

[11] Gary Becker, Elisabeth M. Landes, and Robert T. Michael. An economic analysis of marital instability. Journal of Political Economy, 85(6):1141-1187, 1977.

[12] Gary Becker and H. Gregg Lewis. On the interaction between the quantity and quality of children. Journal of Political Economy, 81(2):S279-S288, 1973. 
[13] Nesha Beharry-Borg, David A. Hensher, and Riccardo Scarpa. An analytical framework for joint vs separate decisions by couples in choice experiments: The case of coastal water quality in tobago. Environmental and Resource Economics, 43(1):95-117, 2009.

[14] Moshe Ben-Akiva and Steven R. Lerman. Disaggregate travel and mobility choice models and measures of accessibility. In Stopher P Hensher D, editor, Behavioral travel modeling, London: Croom Helm, pages 654-679. 1979.

[15] Moshe Ben-Akiva, André Palma, Daniel McFadden, Maya Abou-Zeid, Pierre-André Chiappori, Matthieu Lapparent, StevenN. Durlauf, Mogens Fosgerau, Daisuke Fukuda, Stephane Hess, Charles Manski, Ariel Pakes, Nathalie Picard, and Joan Walker. Process and context in choice models. Marketing Letters, 23(2):439-456, June 2012.

[16] Theodore C. Bergstrom. A fresh look at the rotten kid theorem- and other household mysteries. Journal of Political Economy, 97(5):1138-1159, 1989.

[17] Chandra R. Bhat and Ram M. Pendyala. Modeling intra-household interactions and group decision-making. Transportation, 32:443-448, 2005.

[18] S. M. Bianchi and J. Robinson. What did you do today? Children's use of time, family composition, and the acquisition of social capital. Journal of Marriage and Family, 59(2):332344, 1997.

[19] Paul Bingley and lan Walker. The labour supply, unemployment and participation of lone mothers in in- work transfer programmes. The Economic Journal, 107(444):1375-1390, 1997.

[20] Hans G. Bloemen. The added worker effect in a microeconomic model of the family with market rationing. Technical report, Working paper. Salt Lake city: Brigham Young University, 1989.

[21] Hans G. Bloemen. Income taxation in an empirical collective household labour supply model with discrete hours. Technical report, Tinbergen Institute, January 2010.

[22] Richard Blundell, Pierre-André Chiappori, Thierry Magnac, and Costas Meghir. Collective labour supply: Heterogeneity and non-participation. The Review of Economic Studies, 74(2):417445, 2007. 
[23] Mark Bradley and Peter Vovsha. A model for joint choice of daily activity pattern types of household members. Transportation, 32(5):545-571, 2005.

[24] Tim Callan, Arthur Van Soest, and John R. Walsh. Tax structure and female labour supply: Evidence from ireland. LABOUR, 23(1):1-35, 2009.

[25] Pierre-André Chiappori. Rational household labor supply. Econometrica, 56(1):63-90, 1988.

[26] Pierre-André Chiappori. Collective labor supply and welfare. Journal of Political Economy, 100(3):pp. 437-467, 1992.

[27] Pierre-André Chiappori, André de Palma, Nathalie Picard, and Ignacio A. Inoa. Couple residential location and spouses workplaces. Mimeo, Université de Cergy Pontoise, THEMA, 2013.

[28] Pierre-André Chiappori, Bernard Fortin, and Guy Lacroix. Marriage market, divorce legislation, and household labor supply. Journal of Political Economy, 110(1):37-72, 2002.

[29] Janice Compton and Robert A. Pollak. Proximity and coresidence of adult children and their parents: Description and correlates. Working papers, University of Michigan, Michigan Retirement Research Center, October 2009.

[30] Janice Compton and Robert A. Pollak. Family proximity, childcare, and women's labor force attachment. Technical report, National Bureau of Economic Research, Inc, December 2011.

[31] André de Palma and Karim Kilani. Invariance of conditional maximum utility. Journal of Economic Theory, 132(1):137-146, 2007.

[32] André de Palma, Moez Kilani, and Robin Lindsey. Congestion pricing on a road network: A study using the dynamic equilibrium simulator metropolis. Transportation Research Part A, 39(7-9):588-611, 2005.

[33] André de Palma and Robin Lindsey. Modelling and evaluation of road pricing in paris. Transport Policy, 13(2):115-126, 2006. 
[34] André de Palma, Robin Lindsey, and Nathalie Picard. Departure time choice within the family. Working papers, University of British Columbia, Canada, 2012.

[35] André de Palma and Fabrice Marchal. Real cases applications of the fully dynamic metropolis tool-box: an advocacy for large-scale mesoscopic transportation systems. Networks and Spatial Economics, 2(4):347-369, 2002.

[36] Dick Ettema. Latent activities: Modeling the relationship between travel times and activity participation. Transportation Research Record: Journal of the Transportation Research Board, 1926:171-180, 2006.

[37] Bernard Fortin and Guy Lacroix. A test of the unitary and collective models of household labour supply. The Economic Journal, 107(443):933-955, 1997.

[38] Ora Freedman and Clifford R. Kern. A model of workplace and residence choice in twoworker households. Regional Science and Urban Economics, 27(3):241 - 260, 1997.

[39] John P. Gliebe and Frank S. Koppelman. A model of joint activity participation between household members. Transportation, 29(1):49-72, 2002.

[40] Thomas F. Golob and Michael G. McNally. A model of activity participation and travel interactions between household heads. Transportation Research Part B: Methodological, 31(3):177-194, 1997.

[41] Christian Gourieroux and Alain Monfort. Simulation-based inference: A survey with special reference to panel data models. Journal of Econometrics, 59(1/2):5 - 33, 1993.

[42] Reuben Gronau. Leisure, home production, and work- the theory of the allocation of time revisited. Journal of Political Economy, 85(6):1099-1123, 1977.

[43] Peter Haan. A multi-state model of state dependence in labor supply: Intertemporal labor supply effects of a shift from joint to individual taxation. Labour Economics, 17(2):323 335, 2010.

[44] Torsten Hagerstrand. What about people in regional science? Papers of the Regional Science Association, 24(1):7-21, 1970. 
[45] Jerry Hausman and Paul Ruud. Family labor supply with taxes. The American Economic Review, 74(2):242-248, 1984.

[46] Jerry A. Hausman. Exact consumer's surplus and deadweight loss. The American Economic Review, 71(4):662-676, 1981.

[47] Ignacio A. Inoa, Nathalie Picard, and André de Palma. Effect of an accessibility measure in a model for choice of residential location, workplace, and type of employment. Mathematical Population Studies, page forthcoming, 2014.

[48] Arie Kapteyn, Peter Kooreman, and Arthur van Soest. Quantity rationing and concavity in a flexible household labor supply model. The Review of Economics and Statistics, 72(1):55-62, 1990.

[49] Michael Keane and Robert Moffitt. A structural model of multiple welfare program participation and labor supply. International Economic Review, 39(3):pp. 553-589, 1998.

[50] Hyun-Mi Kim and Mei-Po Kwan. Space-time accessibility measures: A geocomputational algorithm with a focus on the feasible opportunity set and possible activity duration. Journal of Geographical Systems, 5(1):71-91, 2003.

[51] Ryuichi Kitamura, Takamasa Akiyama, Toshiyuki Yamamoto, and Thomas F. Golob. Accessibility in a metropolis: Toward a better understanding of land use and travel. Transport Research Record, 1780:64-75, 2001.

[52] Mei-Po Kwan. Space-time and integral measures of individual accessibility: a comparative analysis using a point-based framework. Geographical Analysis, 30(3):191-217, 1998.

[53] François Laisney. Welfare analysis of fiscal and social security reforms in europe: does the representation of family decision processes matter? Technical report, Final report on EUproject VS/2000/0778, 2002.

[54] Brian HY Lee, Paul Waddell, Liming Wang, and Ram M Pendyala. Reexamining the influence of work and nonwork accessibility on residential location choices with a microanalytic framework. Environment and Planning A, 42(4):913-930, 2010. 
[55] Jane H. Leuthold. An empirical study of female income transfers and the work decision of the poor. Journal of Human Resources, 3(3):312-323, 1968.

[56] Jeremy Lise and Shannon Seitz. Consumption inequality and intra-household allocations. The Review of Economic Studies, 78(1):328-355, 2011.

[57] Shelly Lundberg and Robert A Pollak. Separate spheres bargaining and the marriage market. Journal of Political Economy, 101(6):988-1010, December 1993.

[58] Shelly J. Lundberg, Robert A. Pollak, and Terence J. Wales. Do husbands and wives pool their resources? evidence from the united kingdom child benefit. The Journal of Human Resources, 32(3):463-480, 1997.

[59] Marjorie McElroy and Mary Horney. Nash-bargained decisions: Toward a gen- eralization of the theory of demand. International Economic Review, 22(2):333-349, 1981.

[60] Pierre-Carl Michaud and Frederic Vermeulen. A collective labor supply model with complementarities in leisure: Identification and estimation by means of panel data. Labour Economics, 18(2):159 - 167, 2011.

[61] Harvey J. Miller. Modeling accessibility using space-time prism concepts within geographical information systems. International Journal of Geographical Information Systems, 5(3):287-301, 1991.

[62] Nicolas Moreau and Olivier Donni. Estimation of a collective model of labour supply with taxation. Annales d'Economie et de Statistique, 2002(65):55-83, 2002.

[63] Tijs Neutens, Matthias Delafontaine, Darren M Scott, and Philippe De Maeyer. An analysis of day-to-day variations in individual space-time accessibility. Journal of Transport Geography, 23:81-91, 2012.

[64] Daniele Pacifico. On the role of unobserved preference heterogeneity in discrete choice models of labour supply. Empirical Economics, 45(2):1-35, 2012. 
[65] André de Palma, Nathalie Picard, and Anthony Ziegelmeyer. Individual and couple decision behavior under risk: evidence on the dynamics of power balance. Theory and Decision, 70(1):45-64, 2011.

[66] Nathalie Picard. Démographie et économie de la famille dans les pays en développement / demography and family economics in the developing countries. Economie Publique / Public economics, 03-04(1-2):189-223, 1999.

[67] Nathalie Picard, André de Palma, and Sophie Dantan. Intra-household discrete choice models of mode choice and residential location. International Journal of Transport Economics, XL(3):419-445, 2013.

[68] Ondrej Pribyl and Konstadinos G. Goulias. Simulation of daily activity patterns incorporating interactions within households: Algorithm overview and performance. Transportation Research Record: Journal of the Transportation Research Board, 1926(1):135 141, 2005.

[69] Michael R. Ransom. An empirical model of discrete and continuous choice in family labor supply. The Review of Economics and Statistics, 69(3):465-472, 1987.

[70] Paul A. Samuelson. Social indifference curves. The Quarterly Journal of Economics, 70(1):1-22, 1956.

[71] Darren M. Scott and Pavlos S. Kanaroglou. An activity-episode generation model that captures interactions between household heads: development and empirical analysis. Transportation Research Part B: Methodological, 36(10):875 - 896, 2002.

[72] Amartya Sen. Economics and the family. Asian Development Review, 1:14-26, 1983.

[73] M. William Sermons and Frank S. Koppelman. Representing the differences between female and male commute behavior in residential location choice models. Journal of Transport Geography, 9(2):101 - 110, 2001.

[74] Karthik K. Srinivasan and Sudhakar R. Athuru. Analysis of within-household effects and between-household differences in maintenance activity allocation. Transportation, 32(5):495521, 2005. 
[75] Sivaramakrishnan Srinivasan and Chandra R. Bhat. Modeling household interactions in daily in-home and out-of-home maintenance activity participation. Transportation, 32(5):523544, 2005.

[76] Sivaramakrishnan Srinivasan and Chandra R. Bhat. A multiple discrete-continuous model for independent- and joint-discretionary-activity participation decisions. Transportation, 33(5):497-515, 2006.

[77] Issam M. Srour, Kara M. Kockelman, and Travis P. Dunn. Accessibility indices: Connection to residential land prices and location choices. Transportation Research Record: Journal of the Transportation Research Board, 1805(1):25-34, 2002.

[78] Duncan Thomas. Intra-household resource allocation: An inferential approach. The Journal of Human Resources, 25(4):pp. 635-664, 1990.

[79] Harry Timmermans. Household decision making in travel behaviour analysis. In Ryuichi Kitamura, Toshio Yoshii, and Toshiyuki Yamamoto, editors, The Expanding Sphere of Travel Behaviour Research: Selected Papers from the 11th International Conference on Travel Behaviour Research, pages 159-186. Emerald Group Publishing Limited, Bingley, UK, 2009.

[80] Harry J.P. Timmermans, A. Borgers, J. Dijk, and H. Oppewal. Residential choice behavior of dual earner households: a decompositional joint choice model. Environment and Planning A, 24(4):517-533, 1992.

[81] Harry J.P. Timmermans and Junyi Zhang. Modeling household activity travel behavior: Examples of state of the art modeling approaches and research agenda. Transportation Research Part B: Methodological, 43(2):187 - 190, 2009.

[82] T.A. Townsend. The effects of household characteristics on the multi-day time allocations and travel/activity patterns of households and their members. Ph.D. Dissetation. Department of Civil Engineering, Northwestern University, Evanston, Illinois, 1987.

[83] Arthur Van Soest. Structural models of family labor supply: A discrete choice approach. The Journal of Human Resources, 30(1):pp. 63-88, 1995. 
[84] Frederic Vermeulen. Collective household models: Principles and main results. Journal of Economic Surveys, 16(4):533-564, 2002.

[85] Frederic Vermeulen. Where does the unitary model go wrong? simulating tax reforms by means of unitary and collective labour supply models. the case for belgium. In François Laisney, editor, Welfare analysis of fiscal and social security reforms in Europe: does the representation of family decision processes matter?, Final report on EU-project VS/2000/0778, Mannheim, Centre for European Economic Research. 2002.

[86] Frederic Vermeulen. A collective model for female labour supply with non-participation and taxation. Journal of Population Economics, 19(1):99-118, 2006.

[87] Frederic Vermeulen, Olivier Bargain, Miriam Beblo, Denis Beninger, Richard Blundell, Raquel Carrasco, Maria-Concetta Chiuri, François Laisney, Valérie Lechene, Nicolas Moreau, Michal Myck, and Javier Ruiz-Castillo. Collective models of labor supply with nonconvex budget sets and nonparticipation: A calibration approach. Review of Economics of the Household, 4(2):113-127, 2006.

[88] William Vickrey. Congestion theory and transport investment. The American Economic Review, 59(2):251-260, 1969.

[89] Peter Vovsha, Eric Petersen, and Robert Donnelly. Explicit modeling of joint travel by household members: Statistical evidence and applied approach. Transportation Research Record: Journal of the Transportation Research Board, 1831(1):1-10, 2003.

[90] Peter Vovsha, Eric Petersen, and Robert Donnelly. Impact of intrahousehold interactions on individual daily activity-travel patterns. Transportation Research Record: Journal of the Transportation Research Board, 1898(1):87-97, 2004.

[91] Peter Vovsha, Eric Petersen, and Robert Donnelly. Model for allocation of maintenance activities to household members. Transportation Research Record: Journal of the Transportation Research Board, 1894(1):170-179, 2004. 
[92] Paul Waddell. Accessibility and residential location: The interaction of workplace, housing tenure, residential mobility and location choices. October, 1996. Paper presented at the 1996 Lincoln Land Institute TRED Conference.

[93] Paul Waddell and Firouzeh Nourzad. Incorporating non-motorized mode and neighborhood accessibility in an integrated land use and transportation model system. Transportation Research Record: Journal of the Transportation Research Board, 1805(1):119127, 2002.

[94] Chieh-Hua Wen and Frank Koppelman. Integrated model system of stop generation and tour formation for analysis of activity and travel patterns. Transportation Research Record: Journal of the Transportation Research Board, 1676:136-144, 1999.

[95] Chieh-Hua Wen and Frank Koppelman. A conceptual and methodological framework for the generation of activity-travel patterns. Transportation, 27(1):5-23, 2000.

[96] Seo Youn Yoon and Konstadinos G. Goulias. Constraint-based assessment of intrahousehold bargaining on time allocation to activities and travel using individual accessibility measures. In Proceedings of the 89th Annual Meeting of the TRB. Transportation Research Board, Washington DC, 10-14 January 2010.

[97] Seo Youn Yoon and Konstadinos G. Goulias. Impact of individual accessibility on travel behavior and its propagation through intra-household interaction. Transportation Letters, 2(4):245-260, 2010.

[98] Junyi Zhang and Akimasa Fujiwara. Representing household time allocation behavior by endogenously incorporating diverse intra-household interactions: A case study in the context of elderly couples. Transportation Research Part B: Methodological, 40(1):54 - 74, 2006.

[99] Barry Zondag and Marits Pieters. Influence of accessibility on residential location choice. Transportation Research Record: Journal of the Transportation Research Board, 1902(1):63-70, 2005. 
Appendix: Accessibility measures, by education level

\section{Elementary and Middle School}

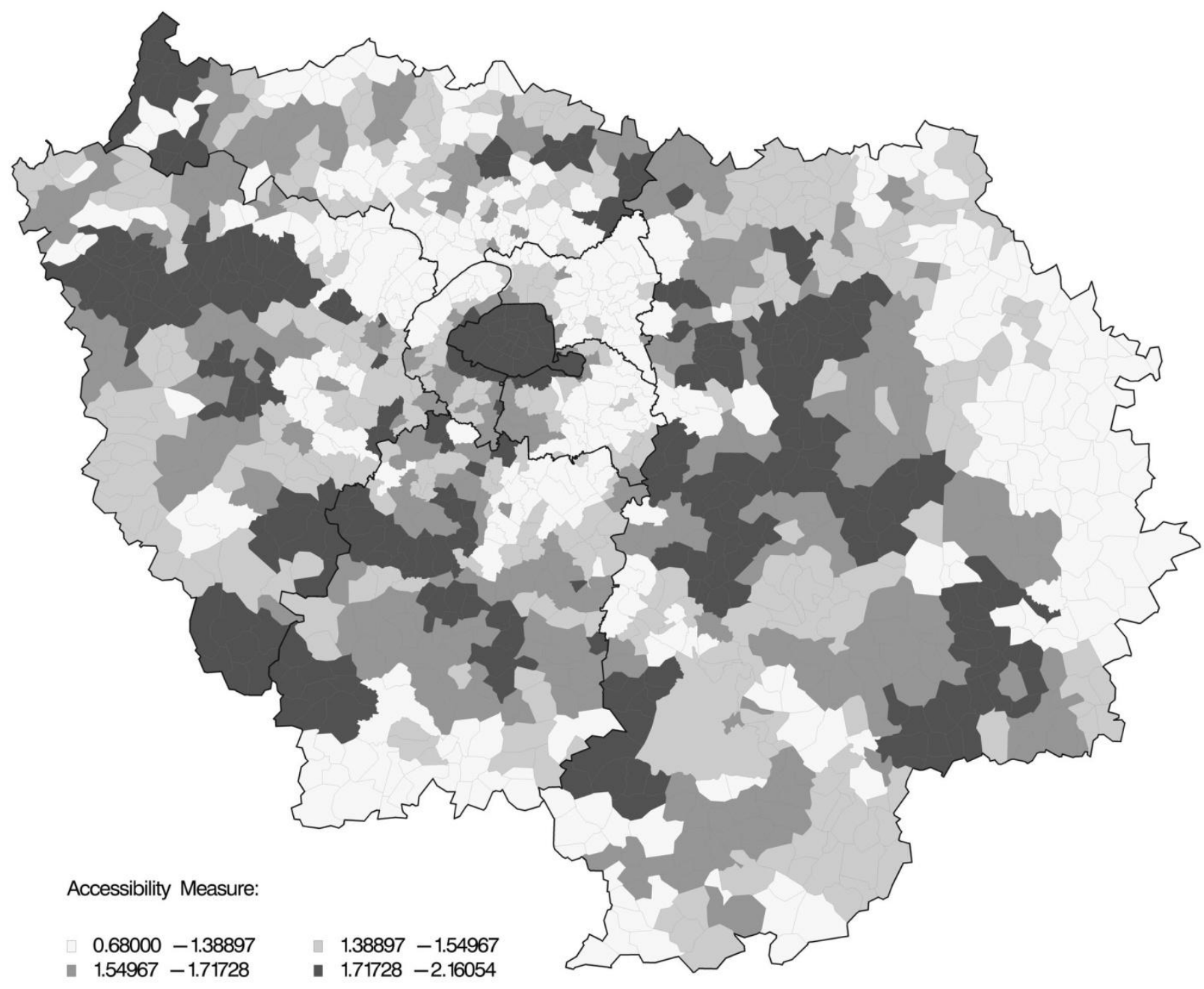




\section{High School}

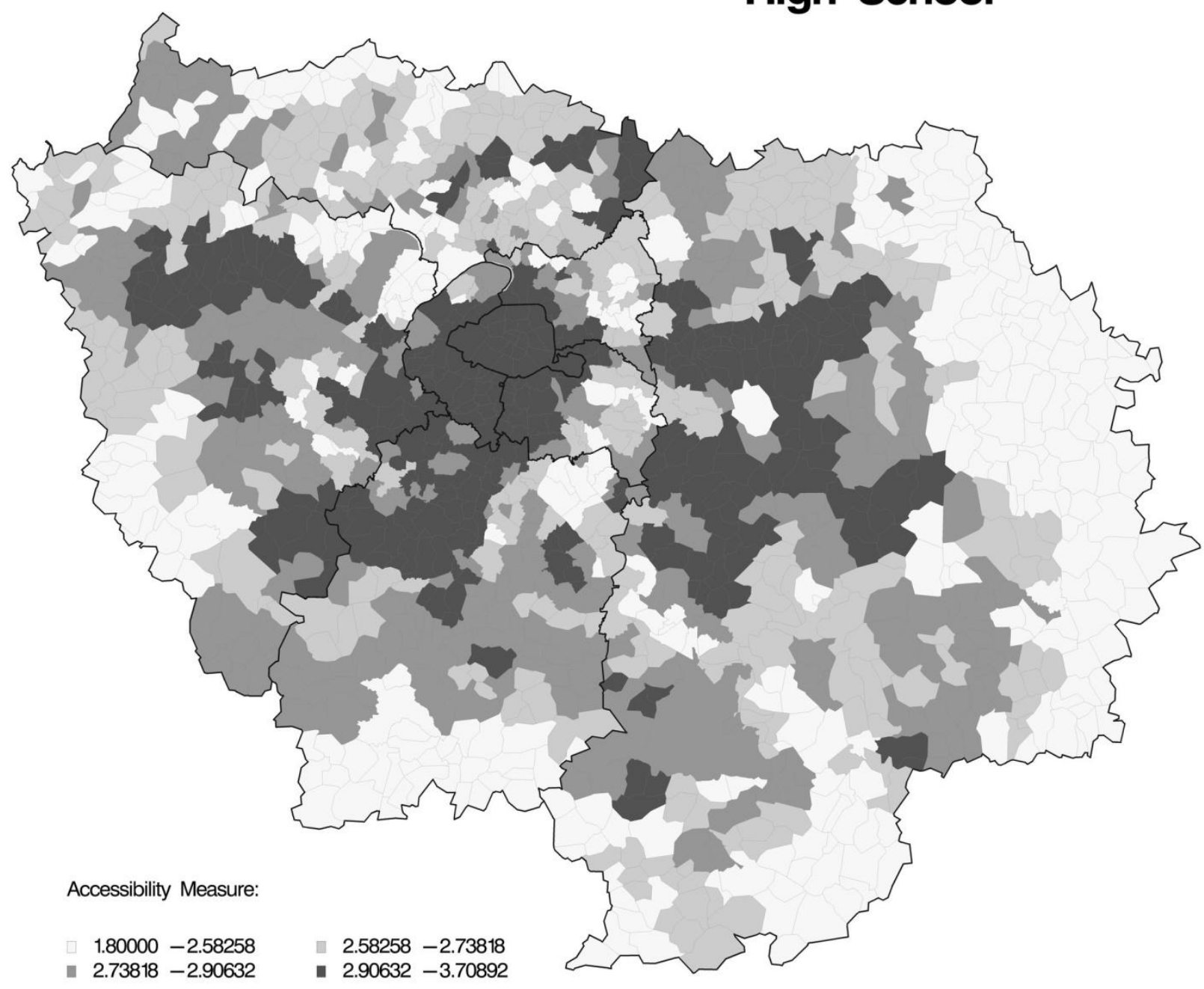




\section{Undergraduate}

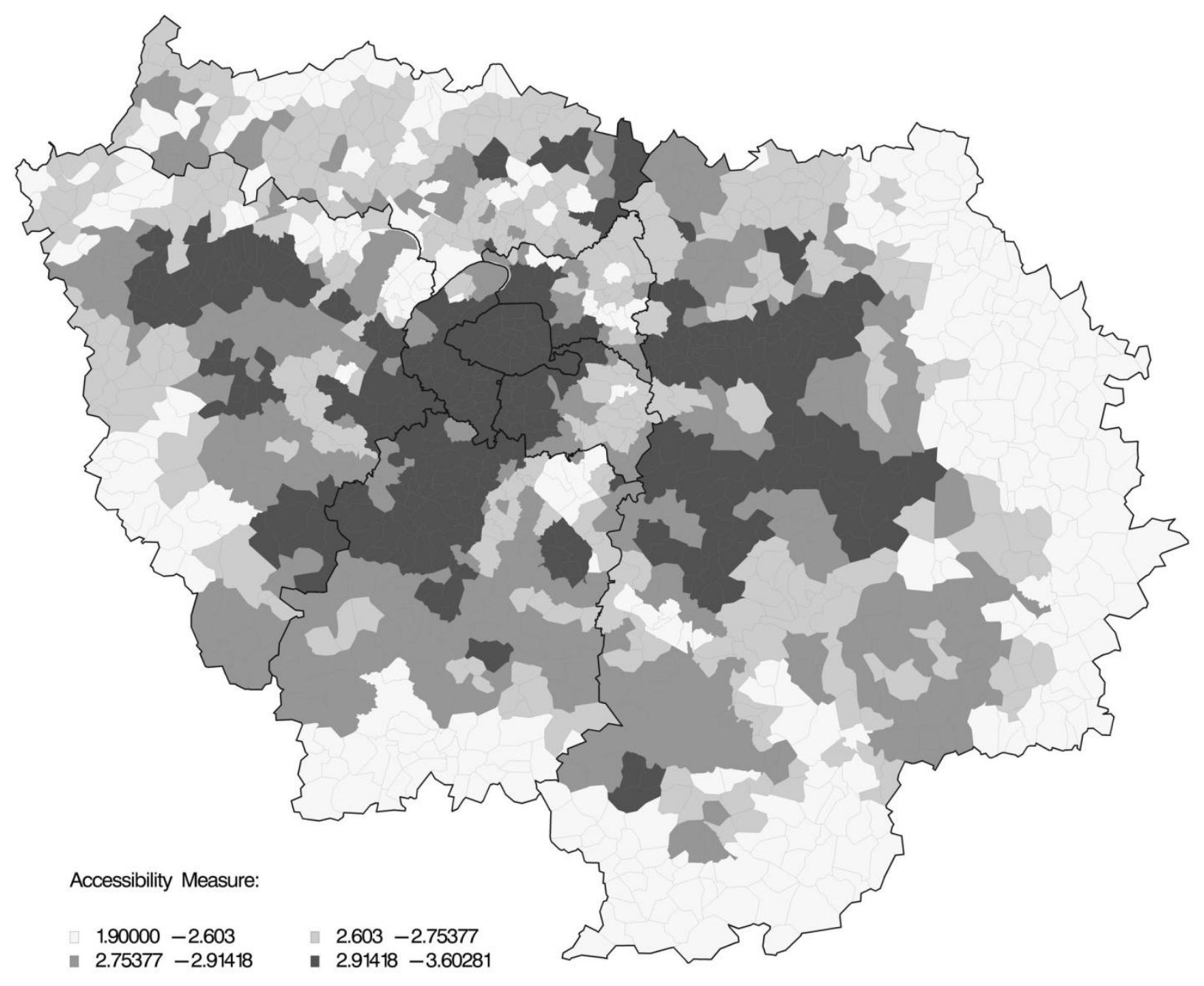




\section{Graduate}

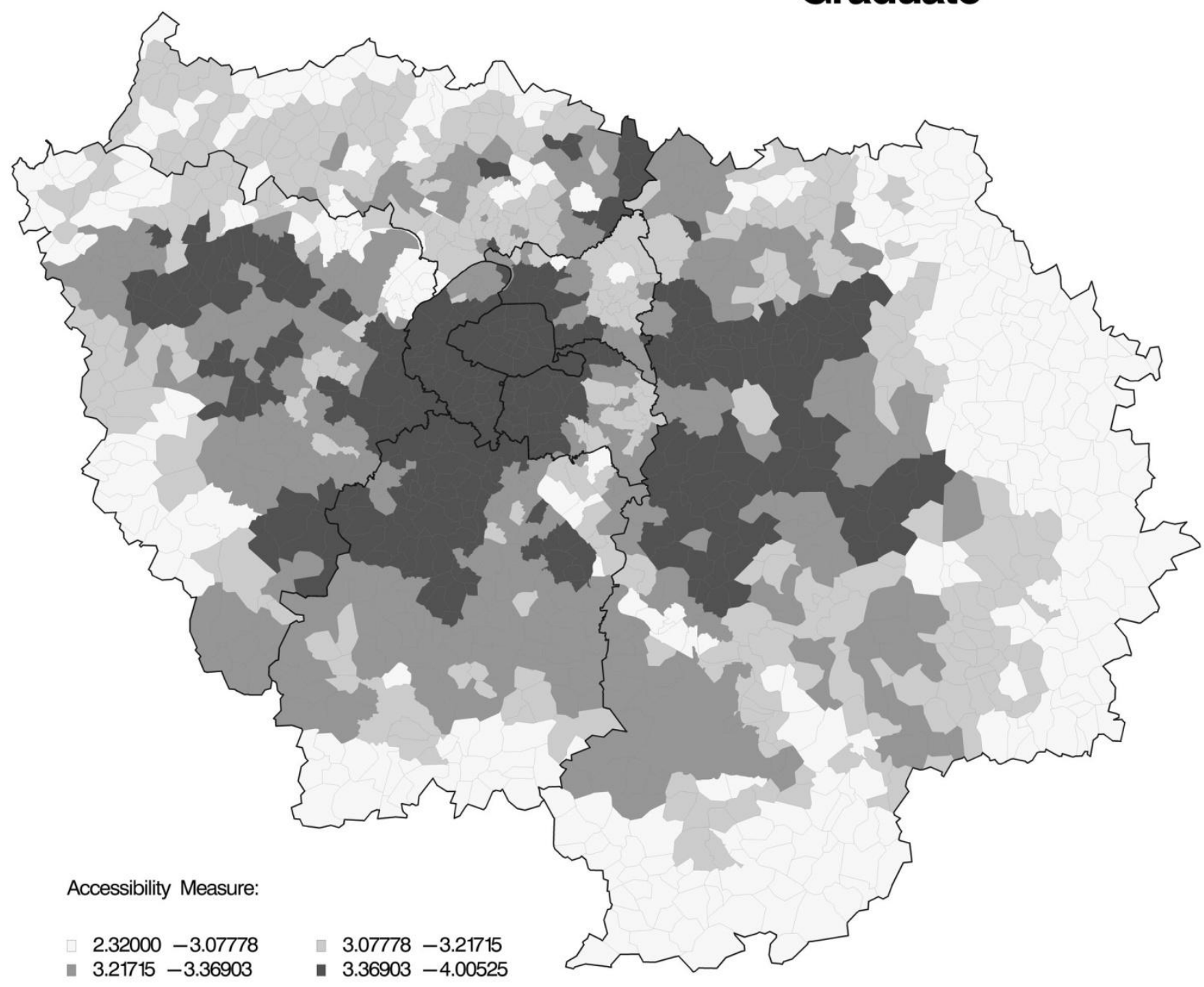

